RESEARCH ARTICLE

\title{
Transcriptional expression of PmrB and arnA within polymyxin-resistant nosocomial isolates of Pseudomonas aeruginosa from India
}

\author{
Sayani Roy ${ }^{1 \#}$, Deepjyoti Paul ${ }^{1 \#}$, Rajkumari Elizabeth ${ }^{1}$, Debadatta Dhar ${ }^{2}$, Atanu Chakarvarty ${ }^{2}$, Amitabha \\ Bhattacharjee $^{1}$ \\ ${ }^{1}$ Department of Microbiology, Assam University, Silchar, India \\ ${ }^{2}$ Department of Microbiology, Silchar Medical College and Hospital, Silchar, India \\ \#Both Sayani Roy and Deepjyoti Paul have contributed equally and may be considered as First Author
}

\begin{abstract}
Objective: The polymyxin group of antibiotics is considered to be one of the most effective antimicrobial agents against many serious pathogenic bacteria, but the excessive use of these antibiotics has led to the development of drug resistance among bacteria. This study was designed to characterize polymyxin-resistant $P$. aeruginosa and to explore the role of PmrB and arnA in resistant phenotype.
\end{abstract}

Methods: mRNA and cDNA of five selected polymyxin-resistant strains representing different MIC range; isolated under normal condition of strain growth, after treating sample/media with $\mathrm{FeCl} 3$ and $\mathrm{MgCl} 2$ alone, or after treating with $\mathrm{FeCl} 3$ and polymyxin antibiotic. The transcriptional expression was observed for $\mathrm{PmrB}$ and arnA by quantitative real time RT-PCR in reference to $P$. aeruginosa PAO1. The presence of plasmid mediated colistin resistance determinants $m c r-1$ was screened by PCR. Susceptibility of the strains was determined by disc-diffusion method and DNA fingerprinting was carried out by performing REP-PCR.

Results: A down regulated expression of $\mathrm{PmrB}$ and arnA was observed even after the unique induction with $\mathrm{FeCl} 3$ and $\mathrm{MgCl}$. All the isolates were found to be resistant against cefepime and different clonal patterns of resistance were found among the isolates.

Conclusion: This study has drawn a new insight into polymyxin resistance which will help in the detection and control of infections caused by multidrug resistant $P$. aeruginosa. The low susceptibility rate to aminoglycoside, piperacllin-tazobactam and ciprofloxacin was found and in addition, detection of PmrB and arnA as molecular markers in the follow up of infections caused by multidrug resistant $P$. aeruginosa. J Microbiol Infect Dis 2018; 8(2):61-68.

Keywords: arnA, mcr-1, PmrB, Polymyxin, Pseudomonas aeruginosa, Multidrug resistance

\section{INTRODUCTION}

Polymyxins, essentially polymyxin B and colistin (polymyxin-E), are the bacterial membrane inhibitors produced from Bacillus spp [1] and are mostly active against Gram negative bacteria [2]. It is an effective drug for the treatment of many serious infections like pseudomonal lung infection, ear, and eye infections [3]. Polymyxins are excreted primarily by the kidneys and are poorly absorbed from the gastrointestinal tract. However, these antibiotics were gradually abandoned in most parts of the word around 1980 because of the reports of their serious toxic effects, mainly on the kidney and nervous system [5-6]. But polymyxins have re-emerged in clinical practice owing to the worldwide increasing prevalence of nosocomial infections caused by multidrug-resistant (MDR) Pseudomonas aeruginosa and Acinetobacter baumannii [7-8]. $P$. aeruginosa is an opportunistic Gram-negative pathogen and is the third leading cause of nosocomial acute infections and fatal chronic lung diseases in patients with cystic fibrosis and immunocompromised individuals [9-10]. Polymyxin-resistant organisms were also reported from many parts of the world [11].

Polymyxin resistance in $P$. aeruginosa occurs mainly through the alteration in the LPS moiety by the addition of 4-amino-4-deoxy-L-arabinose

Correspondence: Dr. Amitabha Bhattacharjee, Department of Microbiology, Silchar Medical College and Hospital, Assam University, Silchar, India E-mail: ab0404@gmail.com

Received: 12 October 2017 Accepted: 20 Mai 2018

Copyright (C) JMID / Journal of Microbiology and Infectious Diseases 2018, All rights reserved 
(LAra4N) to a phosphate group of lipid A [12]. This addition causes an absolute positive increase in lipidA charge, thus lowering the affinity of positively charged polymyxins. PmrAPmrB and PhoP-PhoQ are the main twocomponent regulatory systems for the biosynthesis of LAra4N that confer the polymyxin resistance on the organisms. Recently, mcr-1-mediated acquired colistin resistance has been described in Enterobacteriaceae family [13]. Since polymyxins (polymyxin B and colistin) are considered as last-choice treatment for nonfermenting gram negative bacilli. Increasing resistance pattern of the organisms against this group of antibiotics was reported [8].This study was designed to screen the polymyxin-resistant $P$. aeruginosa and to investigate the role of PmrB and arnA in conferring polymyxin resistance in a tertiary referral hospital of northeast India.

\section{METHODS}

\section{Sample collection}

A total of 290 clinical specimens were collected from the patients who attended or were admitted in different wards and outpatient department of Silchar Medical College and Hospital during September 2013 to August 2014. Duplicate isolates, excluding $P$. aeruginosa, from the same clinical specimen were not included in the study. $P$. aeruginosa strains selected for this study, were characterized and identified by standard biochemical testing, pigment production, growth on cetrimide agar, and 16s rDNA sequence analysis [14].

\section{Screening of polymyxin-resistant $P$. aeruginosa}

All identified $P$. aeruginosa stains were screened by Kirby-Bauer disc diffusion method using the antibiotics polymyxin-B (300 units) and colistin (colistin sulphate; $10 \mu \mathrm{g}$ ) on Muller-Hinton medium (Hi-media, Mumbai, India), in order to select the polymyxin-resistant $P$. aeruginosa strains. The zone dimension was measured and the results were interpreted as per Clinical Laboratory Standard Institute (CLSI) methods [15]. The isolates that showed resistance to either of these two antibiotics were considered as positive. Minimum inhibitory concentration (MIC) was determined for the screened positive
$P$. aeruginosa by agar dilution method against the antibiotics polymyxin-B (Samarth Life Sciences, Mumbai, India) and colistin (Wallace, $\mathrm{HP}$, India) with a range from $2->256 \mu \mathrm{g} / \mathrm{ml}$ and the results were interpreted according to Clinical and Laboratory Standards Institute methods (CLSI 2013) [15].

Genotypic characterization for polymyxin resistance targeting pmrA, PmrB and arnA was performed by PCR assay for all the screened positive isolates. The whole pmrA, PmrB and arnA was amplified and sequenced for all the colistin resistant study isolates The amplified products were purified using MinElute PCR Purification Kit (Qiagen, Germany) then ligated into pGEM-T Vector (Promega, Madison, USA) and sequenced using Sanger sequencing method.

\section{Screening of plasmid mediated colistin resistance (mcr-1)}

The presence of mcr-1 gene was screened by PCR assay for all polymyxin-resistant isolates using the primers CLR5-F (5'CGGTCAGTCCGTTTGTTC-3') and CLR5-R (5'CTTGGTCGGTCTGTAGGG-3') [16].

\section{Transcriptional expression analysis by quantitative real time PCR}

The transcriptional response of $P m r B$ and arnA was observed by performing quantitative Real Time PCR (Applied Biosystem, USA). The primers used in this study are mentioned in Table 1. Five polymyxin-resistant isolates representing different MIC range were selected and $P$. aeruginosa PAO1was used as a reference strain. The isolates were grown in three different conditions. First, all the six strains (including the control) were inoculated in Luria Bertani broth (Hi-media, Mumbai, India) without any chemical or antibiotic pressure. Second, all these six strains were inoculated in Luria Bertani broth containing both $1 \mathrm{mM} \mathrm{FeCl}$ and $\mathrm{MgCl}_{2}$ whereas in the third condition only the five polymyxin-resistant strains were inoculated in Luria Bertani broth with $1 \mathrm{mM} \mathrm{FeCl}_{3}$ and 0.50 $\mu \mathrm{g} / \mathrm{ml}$ of polymyxin B. All these freshly inoculated cultures $(10 \mathrm{ml}$ LB broth in $50 \mathrm{ml}$ of falcon tube) were incubated with shaking (160 rpm) at $37{ }^{\circ} \mathrm{C}$ for $12-16$ hours followed by mRNA isolation. Total mRNA was isolated by using RNeasy mini kit (Qiagen,Hilden, Germany) and 
immediately reverse-transcribed into cDNA using Quantiscript Reverse Transcription kit (Qiagen, Hilden, Germany). The cDNA was quantified by Picodrop (Pico 200, Cambridge, UK). Quantitative real time PCR was performed using Power Sybr Green Master Mix (Applied Biosystem, Warrington, UK) using Step One Plus real time detection system (Applied Biosystem, USA). The relative expression of arnA and $P m r B$ in three different conditions were determined by $\triangle \mathrm{Ct}$ method [17]. The fold change of arnA and $P m r B$ for each sample was normalized against a housekeeping gene rps $L$ of $P$. aeruginosa [18] which was used as an internal standard. Real time PCR was performed and the primers for each target used in separate reaction and each single reaction mixture $(20 \mu \mathrm{l})$ contained 100ng of template cDNA, 10 picomole each for forward and reverse primer (Hysel, New Delhi, India), $10 \mu \mathrm{l}$ of Power SYBER green PCR master mix (Applied Biosystem, Warrington, UK) and $4 \mu \mathrm{l}$ nuclease free water. The reactions were carried out under the following conditions; $95{ }^{\circ} \mathrm{C}$ for $2 \mathrm{~min}, 40$ cycles of $95{ }^{\circ} \mathrm{C}$ for $20 \mathrm{~s}, 52$ ${ }^{\circ} \mathrm{C}$ for $40 \mathrm{~s}, 72{ }^{\circ} \mathrm{C}$ for $30 \mathrm{~s}$.

\section{Antimicrobial susceptibility testing}

Antibiotic susceptibility pattern of polymyxinresistant $P$. aeruginosa was determined by Kirby-Bauer disc diffusion method in order to investigate the therapeutic option for the infections caused by this organism. Susceptibility testing was done against the antibiotics cefepime $(30 \mu \mathrm{g})$, amikacin $(30 \mu \mathrm{g})$, gentamicin $(10 \mu \mathrm{g})$, ciprofloxacin $(5 \mu \mathrm{g})$, piperacillin-tazobactam $(100 / 10 \quad \mu \mathrm{g})$ and imipenem (10 $\mu \mathrm{g})$ (Hi-media, Mumbai, India) and the results were interpreted as per CLSI guidelines (CLSI 2013) [15].

\section{DNA fingerprinting of polymyxin-resistant $P$. aeruginosa}

The heterogeneity in the isolates was determined by repetitive extragenic palindromic (REP) PCR (Applied Biosystem, USA) using primers REP F (5'-XCGXCTTATCXGGCCTAC3') and REP R (5'-NCGNCTTATCNGGCCTAC3') (Hysel, New Delhi, India). PCR was performed according to the following reaction condition; initial denaturation at $95{ }^{\circ} \mathrm{C}$ for $3 \mathrm{mins}$, 30 cycles of denaturation at $95{ }^{\circ} \mathrm{C}$ for $20 \mathrm{~s}$, annealing at $46^{\circ} \mathrm{C}$ for $40 \mathrm{~s}$ and extension at 72
${ }^{0} \mathrm{C}$ for 3mins; and final extension at $72{ }^{\circ} \mathrm{C}$ for 10 mins [19-20].

\section{Statistical analysis}

The statistical power and the sample size of the study were calculated as described previously 21. The sample size and power of the study was determined to verify whether the less number of polymyxin resistance isolates is due to lack of statistical power or have no relation with the sample.

\section{Ethical approval}

The work was approved by Institutional Ethical committee of Assam University, Silchar vide Reference Number: IEC/AUS/C/2014-001. The authors confirm that participants provided their written informed consent to participate in this study.

\section{RESULTS}

\section{Screening for polymyxin-resistant Pseudomonas aeruginosa}

Out of 290 clinical specimens collected between September 2013 and August 2014 from male/female (1:3) in the age range 8-79 years, a total of 163 consecutive, non-duplicate clinical isolates of Pseudomonas aeruginosa were obtained and among them only $21(12.9 \%) P$. aeruginosa isolates were found to be resistant to colistin (polymyxin $\mathrm{E}$ ); but only 20 isolates (12.3\%) showed resistance against polymyxin B, however none of them carried $m c r-1$.The clinical details of these resistant isolates are shown in Table 2. Polymyxin-resistant $P$. aeruginosa showed high MIC pattern against polymyxin B and colistin and most of the strains showed an MIC value of $>256 \mu \mathrm{g} / \mathrm{ml}$ (Table 3). No mutation was obtained in the pmrA, PmrB or arnA sequences based on whole gene sequence analysis. At $5 \%$ level of significance, the power of the study was found to be significant, so the less percentage of polymyxin-resistant Pseudomonas aeruginosa isolates obtained in this study does not have any alliance with the sample size of the study.

\section{Transcriptional analysis}

Transcriptional analysis revealed that the expression levels of $P m r B$ gene in wild strains of polymyxin-resistant $P$. aeruginosa $(\mathrm{RQ}=0.604$ 0.639) was lower than the expression level of control strain Pseudomonas aeruginosa PAO1 
$(\mathrm{RQ}=1)$ (Fig 1, Table 4). A down regulated expression of PmrB (Fig 1) was observed when the cells were treated with $\mathrm{Fecl} 3(\mathrm{RQ}=0.295$ 0.605 ) only or with both polymyxin and $\mathrm{Fecl} 3$ $(\mathrm{RQ}=0.293-0.467)$ when compared with the contron strain of PAO1 (RQ=1). (Fig 1) (Table 4).Under the exposure of $\mathrm{MgCl} 2$, except one strain PAP-4 $(R Q=1.605)$, all the isolates were found to have reduced expression $(R Q=0.439$ $0.667)$ than the control strain $P$. aeruginosa PAO1.

Under normal condition, the expression of arnA in the control strain $(R Q=1)$ was found to be higher when compared with the test sample, whereas under the treatment of $\mathrm{FeCl} 3$ and $\mathrm{MgCl} 2$, the expression was found induced in a single strain respectively such as PAF-9 $(R Q=1.009)$ and $P A P-4(R Q=1.159)$. However, the expression level of arnA was higher than the $P m r B$ when induced with $\mathrm{FeCl} 3$ and the same result was observed even in case, where the cells were treated with both $\mathrm{FeCl} 3$ and polymyxin antibiotics (Fig 2) (Table 4).

\section{Susceptibility pattern of Polymyxin-resistant strains}

Antimicrobial susceptibility results of polymyxinresistant $P$. aeruginosa strains showed low susceptibility rate to amikacin and gentamicin, $\beta$ lactam- $\beta$-lactamase inhibitor (Piperacillintazobactam) and quinolone group (ciprofloxacin) whereas a total resistance was observed in case of third generation cephalosporin (cefepime). Moderate susceptibility rate was observed against imipenem. The results of the susceptibility tests are given in Table 3 .

Table 1: Oligonucleotides used in this study.

\begin{tabular}{|c|c|c|c|c|}
\hline Primer pairs & Target & Sequence (5'-3') & Amplified product size (bp) & Reference \\
\hline $\begin{array}{l}\operatorname{arnA~F} \\
\operatorname{arnA} R\end{array}$ & $\operatorname{arn} A$ & $\begin{array}{l}\text { CATGCCGACGACCCACGGGAA } \\
\text { CAGTTGGCGGATACGCTCCAG }\end{array}$ & 129 & Our study \\
\hline $\begin{array}{l}\text { pmrA F } \\
\text { pmrA R }\end{array}$ & $p m r A$ & $\begin{array}{l}\text { TCACTGAAACGAGGCTGCC } \\
\text { GGACTCCGGTAGGCGGTT }\end{array}$ & 704 & Our study \\
\hline $\begin{array}{l}\text { PmrB F } \\
\text { PmrB R }\end{array}$ & PmrB & $\begin{array}{l}\text { AACCGCCTACCGGAGTCC } \\
\text { AATGCGCAGGCTATCAGAT }\end{array}$ & 1469 & Our study \\
\hline $\begin{array}{l}\text { PmrB RT F } \\
\text { PmrB RT R }\end{array}$ & PmrB & $\begin{array}{l}\text { GCTGAGCGTGGCGGCGCTA } \\
\text { CGGCCTGGTCTTCGGTGGCA }\end{array}$ & 128 & Our study \\
\hline $\begin{array}{l}\text { CLR5-F } \\
\text { CLR5-R }\end{array}$ & $\mathrm{mcr}-1$ & $\begin{array}{l}\text { CGGTCAGTCCGTTTGTTC } \\
\text { CTTGGTCGGTCTGTAGGG }\end{array}$ & 309 & 8 \\
\hline
\end{tabular}

Table 2. Clinical details of patients and characteristics of polymixin-resistant Pseudomonas aeruginosa.

\begin{tabular}{|c|c|c|c|c|c|}
\hline Serial number & Strain ID & Patient's Sex/Age & Clinical specimen & Ward & Clonal Type \\
\hline 1 & PAS-2 & M/35yrs & Pus & Surgery & Type 1 \\
\hline 2 & PAM-11 & F/32yrs & Pus & Orthopaedics & Type 2 \\
\hline 3 & PAP-4 & $\mathrm{F} / 19 \mathrm{yrs}$ & Urine & Paediatrics & Type 2 \\
\hline 4 & PAS-6 & $\mathrm{M} / 26 \mathrm{yrs}$ & Stool & Surgery & Type 6 \\
\hline 5 & PAM-1 & $\mathrm{M} / 45 \mathrm{yrs}$ & Pus & ENT & Type 7 \\
\hline 6 & PAS-1 & $\mathrm{F} / 20 \mathrm{yrs}$ & Pus & Surgery & Type 3 \\
\hline 7 & PAM-4 & $\mathrm{M} / 21 \mathrm{yrs}$ & Urine & Medicine & Type 9 \\
\hline 8 & PAF-9 & $\mathrm{F} / 45 \mathrm{yrs}$ & Pus & ENT & Type 1 \\
\hline 9 & PAS-91 & $\mathrm{M} / 37 \mathrm{yrs}$ & Pus & Surgery & Type 5 \\
\hline 10 & PAM-6 & $\mathrm{F} / 25 \mathrm{yrs}$ & Urine & Medicine & Type 7 \\
\hline 11 & PAM-0 & $\mathrm{M} / 47 \mathrm{yrs}$ & Stool & Medicine & Type 2 \\
\hline 12 & PAM-46 & $\mathrm{F} / 59 \mathrm{yrs}$ & Urine & Medicine & Type 1 \\
\hline 13 & PAS-5 & $\mathrm{M} / 48$ yrs & Pus & Surgery & Type 8 \\
\hline 14 & PAF-3 & $\mathrm{F} / 20 \mathrm{yrs}$ & Pus & Paediatrics & Type 4 \\
\hline 15 & PAP-7 & F/12days & Nasal secretion & Paediatrics & Type 4 \\
\hline 16 & PAO-7 & $\mathrm{M} / 40$ yrs & Pus & Orthopaedics & Type 5 \\
\hline 17 & PAS-2 & $\mathrm{M} / 42 \mathrm{yrs}$ & Urine & Surgery & Type 6 \\
\hline 18 & PAM-3 & M/39 yrs & Sputum & Medicine & Type 6 \\
\hline 19 & PAS-9 & $\mathrm{M} / 53 \mathrm{yrs}$ & Stool & Surgery & Type 9 \\
\hline 20 & PAM-1 & $\mathrm{F} / 1.5 \mathrm{yrs}$ & Oral swab & Medicine & Type 8 \\
\hline 21 & PAO-4 & $\mathrm{F} / 29 \mathrm{yrs}$ & Blood & Paediatrics & Type 3 \\
\hline
\end{tabular}


Table 3: Susceptibility profile of Polymixin resistant Pseudomonas aeruginosa.

\begin{tabular}{|c|c|c|c|c|c|c|}
\hline \multirow{2}{*}{$\begin{array}{l}\text { Serial } \\
\text { number }\end{array}$} & \multirow{2}{*}{$\begin{array}{l}\text { Strain } \\
\text { Code }\end{array}$} & \multicolumn{2}{|c|}{ Screening of polymixin resistance } & \multicolumn{2}{|c|}{$\begin{array}{l}\text { Minimum inhibitory } \\
\text { concentration }(\mu \mathrm{g} / \mathrm{ml})\end{array}$} & \multirow[t]{2}{*}{ Co-resistance profile } \\
\hline & & Polymixin-B & Colistin & Polymixin-B & Colistin & \\
\hline 1 & PAS-2 & Resistant & Resistant & 128 & 64 & CEF,AMK,CIP,PIT \\
\hline 2 & PAM-11 & Resistant & Resistant & $>256$ & $>256$ & CIP, CEF, AMK,GEN \\
\hline 3 & PAP-4 & Resistant & Resistant & 128 & 64 & CEF,AMK,CIP,PIT \\
\hline 4 & PAS-6 & Resistant & Resistant & 128 & 64 & CIP,CEF, AMK,PIT \\
\hline 5 & PAM-1 & Resistant & Resistant & 16 & 16 & CEF,AMK,CIP,GEN \\
\hline 6 & PAS-1 & Sensitive & Resistant & 256 & 128 & $\begin{array}{c}\text { CIP, CEF,AMK,PIT, } \\
\text { IMP }\end{array}$ \\
\hline 7 & PAM-4 & Resistant & Resistant & $>256$ & 256 & PIT, CIP, CEF, AMK \\
\hline 8 & PAF-9 & Resistant & Resistant & $>256$ & $>256$ & CIP, CEF, AMK, PIT \\
\hline 9 & PAS-91 & Resistant & Resistant & 128 & 64 & CIP, CEF, AMK, GEN \\
\hline 10 & PAM-6 & Resistant & Resistant & $>256$ & $>256$ & GEN,CIP,CEF, AMK \\
\hline 11 & PAM-0 & Resistant & Resistant & 256 & 128 & GEN,CIP,CEF,AMK \\
\hline 12 & PAM-46 & Resistant & Resistant & 256 & 128 & PIT, CIP, CEF, AMK \\
\hline 13 & PAS-5 & Resistant & Resistant & $>256$ & $>256$ & PIT, GEN, CEF, AMK \\
\hline 14 & PAF-3 & Resistant & Resistant & $>256$ & $>256$ & GEN, CIP, CEF, AMK \\
\hline 15 & PAP-7 & Resistant & Resistant & 128 & 128 & CIP,CEF,PIT \\
\hline 16 & PAO-7 & Resistant & Resistant & $>256$ & $>256$ & AMK, CEF, CIP, PIT \\
\hline 17 & PAS-21 & Resistant & Resistant & $>256$ & $>256$ & $\begin{array}{c}\text { IMP, GEN, PIT, CIP, } \\
\text { AMK }\end{array}$ \\
\hline 18 & PAM-3 & Resistant & Resistant & $>256$ & $>256$ & GEN, CIP, CEF, AMK \\
\hline 19 & PAS-9 & Resistant & Resistant & $>256$ & $>256$ & IMP, PIT, CIP, CEF \\
\hline 20 & PAS-4 & Resistant & Resistant & $>256$ & 128 & AMK, GEN, CEF \\
\hline 21 & PAM-1 & Resistant & Resistant & 256 & 256 & PIT, GEN,AMK,IMP \\
\hline
\end{tabular}

Table 4. mRNA expression details of clinical isolates of Pseudomonas aeruginosa and PAO1.

\begin{tabular}{|c|c|c|c|c|c|c|c|c|c|}
\hline \multirow[b]{2}{*}{$\begin{array}{l}\text { Sl. } \\
\text { No }\end{array}$} & \multirow[b]{2}{*}{$\begin{array}{c}\text { Strain } \\
\text { Code }\end{array}$} & \multicolumn{4}{|c|}{$\begin{array}{c}\text { RQ values of } P m r B \text { gene in reference to PAO1 } \\
\text { which is assigned to a value } 1\end{array}$} & \multicolumn{4}{|c|}{$\begin{array}{c}\text { RQ values of arnA gene in reference to PAO1 } \\
\text { which is assigned to a value } 1\end{array}$} \\
\hline & & $\begin{array}{l}\text { Wild } \\
\text { strains }\end{array}$ & $\begin{array}{c}\text { Strains } \\
\text { treated } \\
\text { with } \\
\mathrm{FeCl}_{3} \\
\end{array}$ & $\begin{array}{c}\text { Strains } \\
\text { treated } \\
\text { with } \mathrm{PB} \& \\
\mathrm{FeCl}_{3} \\
\end{array}$ & $\begin{array}{l}\text { Strains } \\
\text { treated } \\
\text { with } \\
\mathrm{MgCl}_{2} \\
\end{array}$ & $\begin{array}{l}\text { Wild } \\
\text { strains }\end{array}$ & $\begin{array}{c}\text { Strains } \\
\text { treated } \\
\text { with } \\
\mathrm{FeCl}_{3}\end{array}$ & $\begin{array}{c}\text { Strains } \\
\text { treated } \\
\text { with PB \& } \\
\mathrm{FeCl}_{3} \\
\end{array}$ & $\begin{array}{c}\text { Strains } \\
\text { treated } \\
\text { with } \\
\mathrm{MgCl}_{2}\end{array}$ \\
\hline 1 & PAO1 & $1 \pm .066$ & $1 \pm .04$ & $1 \pm 0.079$ & $1 \pm 0.029$ & $1 \pm .052$ & $1 \pm .091$ & $1 \pm .07$ & $1 \pm 0.049$ \\
\hline 2 & PAM-1 & $\begin{array}{l}0.639 \pm \\
.072\end{array}$ & $\begin{array}{l}0.378 \pm \\
.059\end{array}$ & $\begin{array}{l}0.293 \pm \\
.065\end{array}$ & $\begin{array}{c}0.439 \pm \\
.051\end{array}$ & $\begin{array}{c}0.626 \pm \\
.071\end{array}$ & $611 \pm .081$ & $.645 \pm .038$ & $\begin{array}{c}0.439 \pm \\
.051\end{array}$ \\
\hline 3 & PAP-4 & $\begin{array}{l}0.604 \pm \\
.033\end{array}$ & $\begin{array}{c}0.364 \pm \\
.054\end{array}$ & $\begin{array}{c}0.439 \pm \\
.051\end{array}$ & $\begin{array}{c}1.605 \pm \\
.031\end{array}$ & $\begin{array}{c}0.631 \pm \\
40\end{array}$ & $\begin{array}{l}.609 \pm \\
.034\end{array}$ & $.865 \pm .075$ & $\begin{array}{c}1.159 \pm \\
.042\end{array}$ \\
\hline 4 & PAS-1 & $\begin{array}{l}0.611 \pm \\
.083\end{array}$ & $\begin{array}{l}0.605 \pm \\
.031\end{array}$ & $\begin{array}{c}0.459 \pm \\
.022\end{array}$ & $\begin{array}{l}0.667 \pm \\
.113\end{array}$ & $\begin{array}{l}0.639 \pm \\
.35\end{array}$ & $\begin{array}{l}.739 \pm \\
.129\end{array}$ & $.879 \pm .043$ & $\begin{array}{c}0.605 \pm \\
.031\end{array}$ \\
\hline 5 & PAM-4 & $\begin{array}{l}0.607 \pm \\
.033\end{array}$ & $\begin{array}{l}0.311 \pm \\
.098\end{array}$ & $\begin{array}{c}0.421 \pm \\
.015\end{array}$ & $\begin{array}{c}0.439 \pm \\
.051\end{array}$ & $\begin{array}{c}0.759 \pm \\
.083\end{array}$ & $\begin{array}{c}.613 \pm \\
.039\end{array}$ & $.627 \pm .051$ & $\begin{array}{l}.613 \pm \\
.039\end{array}$ \\
\hline 6 & PAF-9 & $\begin{array}{c}0.628 \pm \\
.027\end{array}$ & $\begin{array}{c}0.295 \pm \\
.046\end{array}$ & $\begin{array}{c}0.467 \pm \\
.074 \\
\end{array}$ & $\begin{array}{c}0.605 \pm \\
.031\end{array}$ & $\begin{array}{c}0.667 \pm \\
.113 \\
\end{array}$ & $\begin{array}{c}1.009 \pm \\
.042\end{array}$ & $.763 \pm .048$ & $\begin{array}{c}0.439 \pm \\
.051\end{array}$ \\
\hline
\end{tabular}




\section{Typing of polymyxin-resistant $P$. aeruginosa strains}

The REP PCR results showed that these polymyxin-resistant $P$. aeruginosa isolates were heterogeneous and revealed ten different clonal types of $P$. aeruginosa strains. Clonal type 1 was found to be the most prevalent type and was detected in 7 isolates (PAS-2, PAM-1, PAS91, PAF-3, PAS-4, PAM-1, PAM-46), followed by type 2 (PAM-6, PAS-9), type 3 (PAS-1, PAS-3), type 4 (PAP-7, PAS-21), type 6 (PAM-11,PAF-9) and clonal type 10 (PAS-6, PAO-7) in two isolates whereas REP types 5(PAM-0), 7(PAS5), 8 (PAP-4) and 9 (PAM-4) were detected in one isolate each (Table 3, Figure 3 ).

\section{DISCUSSION}

Polymyxin antibiotics are considered to be one of the oldest classes of antibiotics having 5 different types A, B, C, D and E but only polymyxin-B and polymyxin-E (colistin) have been used in clinical treatment [7]. Polymyxin antibiotics are most commonly used to treat the infections caused by $P$. aeruginosa and $A$. baumannii and carbapenemase producing Gram negative bacilli. There was a recent report [22] from India showing polymyxin resistance within non-fermenting Gram negative rods. In Asia, most of the studies reported the polymyxin resistance less than 10\%, whereas the resistance rate in $P$. aeruginosa $(>30 \%)$ is higherwhich is contradictory to our study [7]. However, their molecular basis is not described and information in this aspect is lacking in our country [8]. This current study focused on PmrAPmrB component system where PmrA is a regulatory protein of arn operon which plays an important role in polymyxin resistance and $P m r B$ is a sensor kinase protein in the cytoplasmic membrane that activates the transcriptional response of pmrA. In this study, we have observed a unique expression pattern of $P m r B$ as well as arnA in polymyxin-resistant organisms. The q-PCR results showed a down regulated expression of both $P m r B$ and arnA under normal condition of growth in polymyxinresistant organism which disagrees with another study [11]. It is already established that exposure to high levels of Ferric iron in cytoplasm, activates $P m r B$ protein which in turn phosphorylates pmrA. PmrA then regulates the expression of arn operon which is responsible for polymyxin resistance [18]. After exposing the cells with $\mathrm{Fe} 3+$, we failed to get any over expression of PmrB; although (PAF-9; Figure 1) showed some deviation from the other 4 isolates. In case of arn expression, only a single isolate (PAP-4; Figure 2) showed higher expression level of PmrB compared to $P$. aeruginosa PAO1.

Previous reports showed that in A. baumanii, the addition of ferric chloride can induce the expression level of arn operon in pmrAB system and thus can increase the MIC for colistin but there was no evidence of effect of $\mathrm{Fe} 3+$ in the induction of polymyxin resistance in $P$. aeruginosa [23]. Our study has described a down regulation due to low transcriptional expression. However, proteomic level expression analysis which wasnot be performed in this study would prove to be a better mean for understanding PmrB and arnA mediated resistance. Zavaski et al [24] in the year 2007 reported that the majority of $P$. aeruginosa strains used in their study showed the MIC of polymyxin B at $2 \mu \mathrm{g} / \mathrm{ml}$ whereas our study isolates showed an MIC range of 16 to $>256 \mu \mathrm{g} / \mathrm{ml}$ against polymyxin $B$ or colistin which is partly in agreement with the study conducted by Moskowitz et al. [5] where they have found that the $P$. aeruginosa strains isolated from cystic fibrosis patients exhibited MICs of colistin at a concentration greater than $512 \mu \mathrm{g} / \mathrm{ml}$. It was found that most of the study isolates showed resistance to other antibiotics, limiting the treatment option. Typing of all the polymyxin-resistant strains was performed to establish the clonal relatedness among themselves and REP PCR results revealed10 different clonal types of $P$. aeruginosa which were responsible for the spread of polymyxin resistance and no dominant clonal type was responsible for any epidemic spread of this resistance determination this hospital setting.

This study revealed the molecular and genetic background of polymyxin-resistance in $P$. aeruginosa and the transcriptional response has displayed that low level transcription of PmrB and possibly arnA has a role in the polymyxinresistance. Further, there could be some more factors which play a role in translational level of the above mentioned genes which leaves further scope for investigation. This study has drawn a new insight into polymyxin resistance, which with further study will help in devising a detection tool using PmrB and arnA as a molecular marker for detection of multidrug resistant $P$. aeruginosa and its control. 


\section{ACKNOWLEDGMENTS}

Financial Support: The authors would like to acknowledge HOD, Department of Microbiology, Assam University, and Assam University Biotech Hub for providing infrastructural facility. The authors sincerely acknowledge the financial support provided by Council of Scientific and Industrial Research (CSIR Scheme no.37/1632/14/EMR-II) and Department of Biotechnology (DBT-NER twinning Scheme, BCIL/NER-BPCM/2011-1431), Govt. of India to carry out the work.

Conflict of interest: None declared.

\section{REFERENCES}

1) Gupta S, Govil D, Kakar PN, et al. Colistin and polymyxin B: A re-emergence. Indian J Crit Care Med 2009; 13: 49-53.

2) Vaara M. Polymyxins and their novel derivatives. Curr Opin Microbiol 2010; 13: 574-581.

3) Biswas S, Brunel JM, Dubus JC, ReynaudGaubert M, Rolain JM. Colistin: An update on the antibiotic of the $21^{\text {st }}$ century. Expert Rev Anti Infect Ther 2012;10:917-934.

4) Michalopoulos A, Falagas ME. Colistin and Polymyxin B in critical Care. Crit Care Clin 2008; 24: 377-391.

5) Balaji V, Jeremiah SS, Baliga PR. Polymyxins: Antimicrobial susceptibility concerns and therapeutic options. Indian J Med Microbiol 2011; 29:230-242.

6) Falagas ME, Michalopoulos A. Polymyxins: old antibiotics are back. Lancet 2006; 367:633-634.

7) Falagas ME, Rfailidis PI, Matthaiou DK. Resistance to Polymyxins: Mechanisms, frequency and treatment options. Drug Resist Updat 2010; 13:132-138.

8) Gupta V, Bansal N, Palta S, Gombar S, Chaner J. Comparative in vitro activity of polymyxins against carbapenem susceptible and resistant nonfermenters from critically ill-patients. Indian J Med Microbiol 2014;32:203-204.

9) Fernandez L, Gooderham WJ, Bains M, McPhee JB, Wiegand I, Hancock REW. Adaptive Resistance to the "Last Hope" antibiotics polymyxin B and Colistin in Pseudomonas aeruginosa is mediated by the novel twocomponent regulatory system ParR-ParS. Antimicrob Agents Chemother 2010; 54: 3372-82.

10) Paul D, Dhar D, Maurya AP, et al. Occurrence of co-existing blaVIM-2 and blaNDM-1 in clinical isolates of Pseudomonas aeruginosa from India. Ann Clin Microbiol Antimicrob (2016) 15:31.doi 10.1186/s12941-016-0146-0.

11) Moskowitz SM, Brannon MK, Dasgupta N, et al. PmrB Mutations Promote Polymyxin Resistance of
Pseudomonas aeruginosa Isolated from ColistinTreated Cystic Fibrosis Patients. Antimicrob Agents Chemother 2012; 56:1019-30.

12) Deng $D$, Phan $M$, Sharma $A$, Sharma $M$. RpoS and $P m r A$ induced resistance to polymyxin $B$ is independent of arnT expression in Pseudomonas aeruginosa. J Exp Microbiol Immun 2013; 17: 5559.

13) Liu YY, Wang Y, Walsh TR, et al. Emergence of plasmid-mediated colistin resistance mechanism MCR-1 in animals and human beings in China: a microbiological and molecular biological study. Lancet Infect Dis 2016; 16:161-168.

14) Colee JG, Diguid JP, Fraser AG. Mackie and McCartney Practical Medical Microbiology. 1996; $14^{\text {th }}$ ed, Edinburgh: Churchill, Livingstone.

15) Clinical Laboratory Standard Institute. Performance Standards for Antimicrobial Susceptibility Testing; Twenty-Third Informational Supplement. 2013; M100-S23. CLSI, Wayne, USA.

16) Elnahriry SS, Khalifa HO, Soliman AM, et al. Emergence of Plasmid-Mediated Colistin Resistance Gene mcr-1 in a Clinical Escherichia coli Isolate from Egypt. Antimicrob Agents Chemother 2016; 60:3249-3250.

17) Paul D, Bhattacharjee $A$, Bhattacharjee $D$, Dhar $D$, Maurya AP, Chakravarty A. Transcriptional analysis of blaNDM-1 and copy number alteration under carbapenem stress. Antimicrob Resist Infect Control 2017; 6, 26.

18) Mesaros N,Glupczynski Y, Avrain L, Caceres NE, Tulkens PM, Bambeke FV. A combined phenotypic and genotypic method for the detection of Mex efflux pumps in Pseudomonas aeruginosa. J Antimicrob Chemother 2007; 59:378-386.

19) Versalovic J, Koeuth T, Lupski JR. Distribution of repetitve DNA sequences in eubacteria and application to fingerprinting of bacterial genomes. Nucleic Acids Res1991; 19:6823-6831.

20) Paul D, Maurya AP, Chanda DD, Sharma GD, Chakravarty A, Bhattacharjee A. Carriage of blaNDM-1 in Pseudomonas aeruginosa through multiple Inc type plasmids in a tertiary referral hospital of northeast India. Indian $\mathrm{J}$ Med Res 2016; 143: 826-829.

21) Suresh KP, Chandrashekara S. Sample size estimation and power analysis for clinical research studies. J Hum Reprod Sci 2012; 5:7-13.

22) Grewal US, Bakshi R, Walia G, Shah PR. Antibiotic susceptibility profiles of non-fermenting Gram-negative bacilli at a tertiary care hospital in Patiala, India. Niger Postgrad Med J 2017; 24: 121-125.

23) Adams MD, Nickel GC, Bajaksouzian S, et al. Resistance to colistin in Acinetobacterbaumanii associated with mutations in the PmrAB two component systems. Antimicrob Agents Chemother 2009;53: 3628-3634. 
24) Zavascki AP, Goldani LZ, Natiion RL. Polymyxin-B

for the treatment of multidrug-resistant pathogens:

a critical review. J Antimicrob Chemother 2007;

60:1206-15. 